\title{
Smart urban freight planning process: integrating desk, living lab and modelling approaches in decision-making
}

\author{
Valerio Gatta $^{1}$ - Edoardo Marcucci ${ }^{1,2} \cdot$ Michela Le Pira $^{1,3}$ (D)
}

Received: 16 August 2016/Accepted: 9 May 2017 / Published online: 6 June 2017

(C) The Author(s) 2017. This article is an open access publication

\begin{abstract}
Purpose This paper proposes an innovative approach to decision-making processes for urban freight planning that could easily be transferred across cities while capable of jointly taking into account: (1) all the conceivable and updated urban freight transport (UFT) measures that should apply to the specific city culture, structure and evolution, (2) all the relevant stakeholders and successfully involve them from the beginning, (3) behavioural, technical, operational, organisational and financial issues.

Methods The methodology is organised and deployed in three phases, following three different approaches, i.e.: a "desk approach" for data acquisition and knowledge-based policy rankings; a "living lab approach" to foster stakeholders' engagement in co-creating policies; a "modelling approach" to evaluate policies and find/define an optimised mix of shared applicable/effective policies.

Results The three-phase methodology supports public authorities in: (a) increasing knowledge and understanding of the most innovative context-specific UFT policies; (b) integrating UFT policies in strategic urban planning via collaborative participation/governance processes; (c) developing an ex-ante
\end{abstract}

This article is part of Topical Collection on The role of planning towards sustainable urban mobility

Michela Le Pira

michela.lepira@uniroma3.it

1 Department of Political Sciences, University of Roma Tre, Rome, Italy

2 Department of Logistics, Molde University College, Molde, Norway

3 Department of Civil Engineering and Architecture, University of Catania, Catania, Italy behaviourally consistent, financially robust and technically compatible assessment of shared UFT policy mixes while providing appropriate instruments to facilitate policy adoption and deployment.

Conclusions The proposed methodology contributes to the identification and development of effective UFT solutions. Bringing together knowledge acquisition, policy co-creation, behaviour change analysis within a single methodological approach, aimed at identifying an optimised policy package, is both new and needed.

Keywords City logistics · Urban freight transport - Innovative solutions $\cdot$ Behavioural models

\section{Introduction}

The European Union (EU) is largely urbanised. ${ }^{1}$ Urban freight transport (UFT) is an increasingly relevant part of modern city life determining ec.onomic advantages and contributing to well-being while, also, generating relevant social costs. Managing UFT requires local policy-makers striking a balance between throughput, liveability, safety and sustainability. The complexity characterising the UFT framework aggravates this daunting task. Heterogeneous stakeholders living in cities, in fact, interact, both competing and cooperating, and, often, are characterised by contrasting objectives. Stakeholders can be generally defined as those who hold an interest in the decision to be made, even if they have no formal role in the decisionmaking process (i.e. they are not the final decision-makers) [2] . The main UFT actors pertain both to the private and public sphere and they can be categorised in: (1) shippers; (2) freight carriers; (3) receivers; (4) residents; (5) planners and regulators

\footnotetext{
${ }^{1} 72 \%$ of the total population live in cities, reaching $80 \%$ by 2020 [1].
} 
$[3,4]$. Shippers generate freight demand, freight carriers organise freight transport from shippers to receivers and they are all driven by private interests. Planners/regulators have to define the overall framework under which transport providers perform the delivery tasks so to minimise the negative impacts UFT has on cities and residents. All these categories' interests need to be taken into account when deciding about UFT policies. Besides, any innovative solution should explicitly consider and account for its behavioural implications when identifying the levers used to influence present trends so to address the sustainability challenges UFT poses to modern cities [5-7]. Under this respect, freight behaviour research is a fundamental, yet understudied, subject [8].

Specific trends within UFT (e.g. e-commerce growth) influence both the type and dimension of the challenges policymakers will be confronted with in the near future. Various measures have been considered (regulatory; market-based; land use planning and infrastructure; new technologies) and there is hefty evidence that no single solution can address and solve all UFT problems [9]. Rather, an integrated policy package approach is needed [10]. Furthermore, ever-increasing demand for a better city-life quality suggests promoting a greater integration among freight activities within the urban transportation system. At the same time, however, the peculiarities of various cities in terms of legislation, regulation, infrastructures, network, urban configuration and social habits call for context-specific UFT measures [11].

It is necessary to understand the root causes that produce UFT related problems and this can lead to more appropriate and, therefore, effective solutions [12]. In general, serving local businesses and homes in cities is inefficient mainly because of multiple - non consolidated - deliveries to many destinations and also because of the constraints on routing and scheduling posed by restrictions to certain routes or time periods. Besides, home deliveries is even more inefficient due to several reasons, among which the spatial dispersion of residences and the frequency of failed deliveries [13].

UFT policy interventions sometimes grind to a halt or produce unintended results also due to the decision-making process adopted for their selection. In fact, the often too typical "decide and defend" approach, but also participatory decision-making processes, when void of both behavioural impact and ex-ante business model assessment, do not constitute a robust base for an optimised policy selection capable of guaranteeing the desired results. To produce long-lasting effects one should, coherently and co-ordinately, evaluate selected policies accounting for the pre-existing city planning framework.

The main shortcomings motivating the methodological approach proposed in this paper refer to: 1) incomplete understanding of UFT problems and challenging solutions, 2) scant coordination between urban transport and logistics stakeholders, 3) lack of information/understanding related to behavioural issues and, 4) insufficient and uncoordinated urban logistics strategies among local policy-makers producing a limited integration of UFT policies with the overall urban mobility system.

This paper proposes an innovative decision-making process for urban freight planning, easily transferable across cities and capable of jointly: (a) accounting for conceivable UFT measures applicable to the specific city culture, structure and their likely evolutions, (b) considering and involving all relevant stakeholders in the planning process, (c) integrating behavioural, technical, operational, organisational and financial issues.

Three distinct yet complementary phases constitute the backbone of the methodology, which is innovative since it is a well-thought-out combination of well-established methods in a single integrated methodological framework. Outcomes of cutting-edge UFT research and innovative initiatives represent its main inspirations. More in detail:

- Phase 1 - "desk approach" produces a preliminary logistic city profile [14]. This task is performed using info on city, stakeholders and freight characteristics. Subsequently, an $e x-$ ante and context-specific policy ranking is defined via problem capture techniques cross-referenced to a policy database.

- Phase 2 - "living lab approach" [15] refines the policies selected, improves and transforms them, using a collaborative governance model approach so to include them within a sustainable urban mobility plan (SUMP) framework, thus defining a shared policy subset thanks to an active/fruitful involvement of relevant stakeholders in a long-lasting/integrated planning process.

- Phase 3 - "modelling approach" focuses on the most appropriate behavioural stimuli capable of favouring policy implementation/adoption, based on differentiated yet integrated state-of-the-art policy assessment methodologies (e.g. behavioural and business model analysis) coupled with ITS/gamification tools, and it provides policymakers with an efficient, effective and innovative decision-support system.

The three-phase methodology is intended for experts to support local public authorities (i.e. the decision-makers) by: 1) increasing knowledge and understanding of the most innovative, promising context-specific UFT policies; 2) integrating UFT policies in strategic urban planning via collaborative participation/governance processes; 3 ) developing an ex-ante behaviourally consistent, financially robust and technically compatible assessment of shared UFT policy mixes while providing appropriate instruments to facilitate policy adoption and deployment (Fig. 1).

The organisation of the paper is the following: section 2) reviews the state of the art of current approaches to UFT policy-making with a focus on recent and significant UFT 
Fig. 1 Framework of the proposed decision-making process

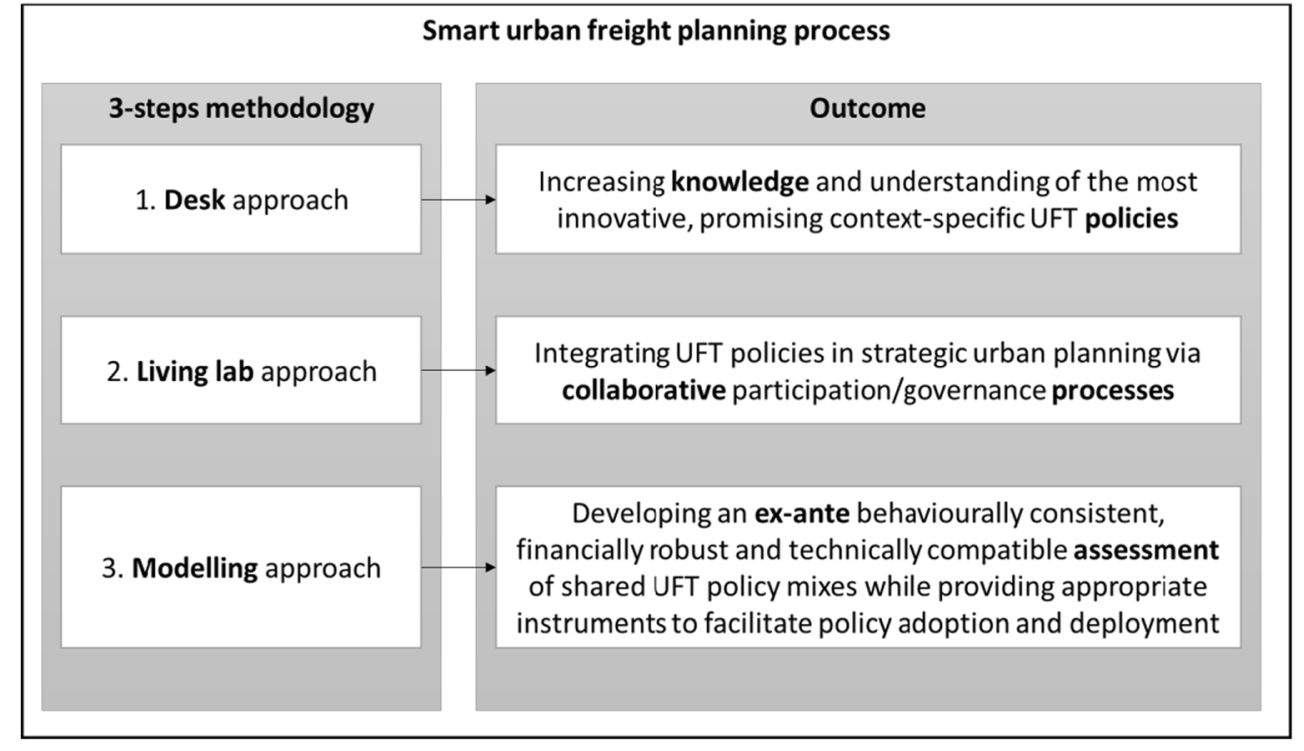

innovative research streams and initiatives; section 32) presents the main elements and steps of the proposed methodological approach; section 4) derives relevant implications for UFT policy-making, discussing the potential of the integrated approach; section 5) concludes summarizing the main concepts.

\section{Literature review}

The traditional planning approach related to urban transport relies on studying transport demand to find and support solutions mainly related to passenger mobility. This is, in fact, the predominant component of overall mobility while freight is often neglected [16]. Lately, a fast-growing awareness of the strategic importance UFT plays and the related negative impacts it causes at city level has produced an increase in the research efforts made to define and implement sustainable UFT solutions. UFT planning should be considered within the overall urban mobility framework, as suggested by the Sustainable Urban Mobility Plan (SUMP) approach [17]. ${ }^{2}$ UFT planning and Sustainable Urban Logistic Plans (SULPs) are to be included as essential components of SUMPs [18-20].

Over the past 15 years, a range of UFT research and innovation initiatives have proposed solutions to tackle the problems caused by urban freight deliveries (e.g. CIVITAS I, II, PLUS, PLUS II). Several projects have also been devoted to collecting and deploying UFT best practices (e.g. BESTUFS I, II, BESTFACT, TIDE, SUGAR). Nevertheless, there is a general lack of detailed

\footnotetext{
$\overline{2}$ Sustainable Urban Mobility Plans (SUMPs) aim at devising and developing "measures to improve the efficiency of urban logistics, including urban freight delivery, while reducing related externalities like emissions of GHG, pollutants and noise" [17].
}

knowledge needed to address UFT issues by local policymakers and substantial opportunities for improvement still persist. In fact, a fair amount of UFT-related programmes has been characterised by a non-negligible failure rate. This is mainly attributable to the insufficient commitment from relevant stakeholders. Involving stakeholders early on in the process, on the contrary, usually produces better results [21]. Unsatisfactory results also derive from research projects based on real-life implementations of innovative UFT solutions. Although many initiatives proved successful in pilots and demonstrations, large-scale adaptations did not take place. The reasons for failures differ. However, one common feature is that only few initiatives consider all stakeholders and jointly test all possible solutions. In some cases, the implementations terminate shortly after public funding comes to an end [11]. These considerations call for an in-depth investigation, often not performed, of the financial sustainability of the solutions proposed.

Besides, innovative and well-grounded decision-support systems (DSS) are necessary to deal with the complexity characterising UFT environment and participatory decisionmaking. Three elements are fundamental and strictly interlaced to make a DSS effective and efficient: data, models and simulations. Understanding, predicting and interpreting stakeholders' behaviours to policy interventions requires data and models to produce suitable hypothetical scenarios simulations and ex-ante evaluations of their likely acceptability and effects. Under this respect, an innovative approach promotes the combination of disaggregate behavioural freight models (e.g. discrete choice models - DCMs), and dynamic simulations (e.g. agent-based modelling - ABM). In fact, while DCMs can adequately elicit stakeholders' individual preferences based on sound microeconomic theory [9, 22, 23], 
ABMs can simulate and reproduce interaction in a participatory decision-making process where stakeholders can influence each other's decisions [24-26].

Behaviour change is an important aspect policy-makers should focus on to boost the success probability of the strategies adopted. Indeed, freight demand strategies ${ }^{3}$ mostly concentrate on changing receivers' behaviour, those who generate transport demand[27]. This has a greater potential for improving the economic, social, and environmental performance of urban freight systems [8]. ${ }^{4}$ While incentives are useful to foster UFT behaviour change, a recent trend aims at engaging and promoting sustainable behaviours using "gamification" techniques, i.e. the use of game design elements in nongame contexts [28]. Gamification is gaining popularity in the mobility domain ${ }^{5}$ (e.g. [29-33]). However, to be effective, it needs to be appropriately conceived, deployed and managed. A user-centred, behaviourally consistent design approach is desirable. One can pursue this by using stated choice experiments and DCMs to combine game characteristics and tailor them to the gamified context, thus aligning them with agents' preferences and expectations [33]. This will maximise each agent-type engagement and behaviour change potential. In this respect, gamification can stimulate sustainable UFT behaviours.

Another key issue is finding effective ways to improve freight movement and logistics' activities efficiency. The concept of "Physical Internet" [34], as a metaphor of the Digital Internet, has been recently introduced "to propose a vision for a sustainable and progressively deployable breakthrough solution to global problems associated with the way we move, handle, store, realise, supply and use physical objects all around the world" (from the Physical Internet Manifesto [35]). Physical Internet aims at developing a "Hyper-connected City Logistics", a conceptual framework for designing significantly more efficient and sustainable urban logistics and transportation systems assuming full-fledged interconnected cities and logistics activities [34].

Considering all the discussed issues and concepts together, it is evident the need of a comprehensive and innovative approach to decision-making in urban freight planning. To this end, this paper proposes, discusses and illustrates a set of procedures, models and tools to select an optimised mix of shared, applicable, effective and financially sustainable UFT

\footnotetext{
${ }^{3}$ Holguín-Veras and Sánchez-Díaz [8] define freight demand strategies as "the area of transportation policy that seeks to induce the demand generator to enact changes in demand patterns to increase economic productivity and/or efficiency; and/or enhance sustainability, quality of life, and/or environmental justice."

4 "Examples include: off-hour delivery programs that incentivize receivers to accept deliveries in the off-hours; staggered pick-up/delivery programs that induce receivers to spread their deliveries throughout the day; and ReceiverLed Consolidation programs that encourage receivers to reduce their Freight Trip Generation" [8].

5 e.g. CIVITAS Training: Influencing behavior through gamification (http:// www.civitas.eu/content/civitas-training-influencing-behaviour-throughgamification)
}

policy measures, aimed at improving city logistics efficiency while accounting for agents' heterogeneous preferences and deep-rooted interactions characterising this complex environment.

\section{Methodology}

\subsection{Desk approach to understand cities}

Desk approach is core to the first phase and focuses on providing a preliminary well-thought list of city-specific candidate policies representing the starting point for further stakeholders' evaluation (Fig. 2). City logistic profiles are acquired on the base of specific city, stakeholders and freight characteristics [14] that, all together, allow to define the root causes that produce the problems to be solved (as explained in section 1) and the objectives the policy-maker should aim at. The profiles characterise the logistic vocation, e.g. large commercial stores, business centre, residential areas with local trade [14]. Then, thanks to scientific knowledge, problems are captured and cross-referenced with a policy database that draws on urban freight best practices, producing an ex-ante context-specific policy ranking.

The main tools available are:

1. Open data sources: "open" data sources are used to complement city-provided data to enhance knowledge and improve modelling inputs. This compensates for the general lack of data representing one of the main factors hindering the development of next-generation UFT models which, in turn, may limit effective policy-making and operations management.

2. Scientific knowledge: it consists of performing and periodically updating a wide-ranging and well-structured scientific literature survey concerning UFT policy covering: measures, effects, controversial issues, interactions, etc. This will provide a consistent, updated, interdisciplinary, relevant, possibly exhaustive mapping of the contributions appearing in scientifically well-respected journals.

3. Urban freight best practices: measures adopted and goals expected from UFT real-life implementation are classified and evaluated according to: a) temporal reference scale (strategic, tactical, and operative), b) decision-makers involved, c) number and type of goals pursued.

4. Policy database matching: it includes two activities: a) creating an extensive and typified policy database based on the results obtained in EU-funded projects (e.g. CITYFREIGHT; CITYLOG; C-LIEGE; LAMILO; NICHES; SMARTSET; etc.), as well as in national and regional ones, and drawing on the urban freight best practices previously acquired; b) developing a matching algorithm/software to determine the best possible 
Fig. 2 Description of the first phase "desk approach"

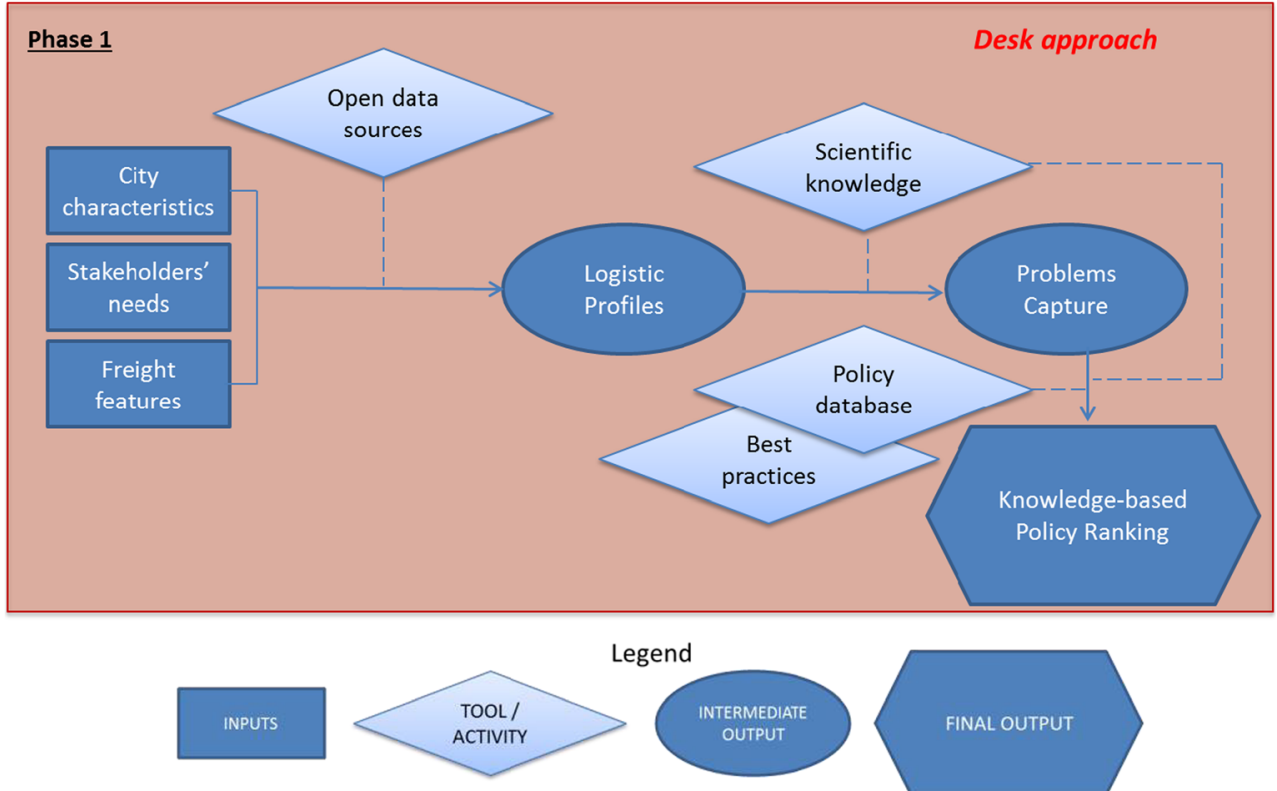

combination between policy database and outputs of the previous activities (i.e. logistic profiles and problems capture).

\subsection{Living lab approach for policy planning}

The second phase relies on a "living lab approach", where cities operate as innovation promoting contexts to stimulate implementation processes for public and private measures to contribute to increased efficiency and sustainable urban logistics [15]. A living lab is defined as a dynamic environment built to test project solutions in real-life contexts (e.g. cities) where several implementations performed by different stakeholders run in parallel [36]. A city logistics living lab environment comprises three layers: strategic, practical and ex-post results observation, enabling a "feedback loop" to decide for new directions and possibilities of the living lab [37].

Following the living lab concept, the policies selected in phase 1 are refined adopting a collaborative governance model approach supporting their consideration for inclusion within SUMPs. The sub-set of shared policy measures is obtained thanks to an active and fruitful promotion of relevant stakeholders' involvement in a long-lasting/integrated planning process (Fig. 3).

The two main pillars are:

1. Stakeholder engagement: it is the prerequisite for a successful setup of a living lab environment [38] capable of producing jointly desirable solutions, departing from the consolidated Asian Development Bank methodology [39]. Actions needed are: a) clarify stakeholder involvement purposes; b) define stakeholders to involve; c) motivate the previous point); d) discuss methods for achieving involvement; e) explain who should organise the process. Appropriate tools, such as Multi-Actor Multi-Criteria Analysis, can be used to account for stakeholders' preferences in evaluating alternatives [40, 41].

2. Integrated planning: it consists of coordinating spatial, temporal and technical planning activities to promote the achievement of the goals set. The process focuses on methods to integrate collaborative governance model outputs into SUMP while also considering the specific city planning status quo situation. SUMP standard cycle [42] constitutes the starting point for the integration of different planning and stakeholder engagement activities.

\subsection{Modelling approach for policy evaluation and facilitation}

The last phase consists of policy evaluation via differentiated yet integrated policy assessment methodologies and facilitation, providing the most appropriate behavioural stimuli capable of favouring policy implementation developed thanks to innovative ICT-based tools, thus supporting local policymakers' decisions via a reliable and innovative DSS (Fig. 4).

The objective is to collate a well-balanced set of integrated assessment methods capable of facilitating the coherent and successful deployment of effective, applicable and, possibly, financially sustainable solutions. This set of activities could include a variety of tools both aimed at policy assessment (points 1, 2, 3 and 4 of the list reported below) and policy implementation with the final goal of promoting relevant behavioural changes (points 5 and 6): 
Fig. 3 Description of the second phase "Living Lab approach"

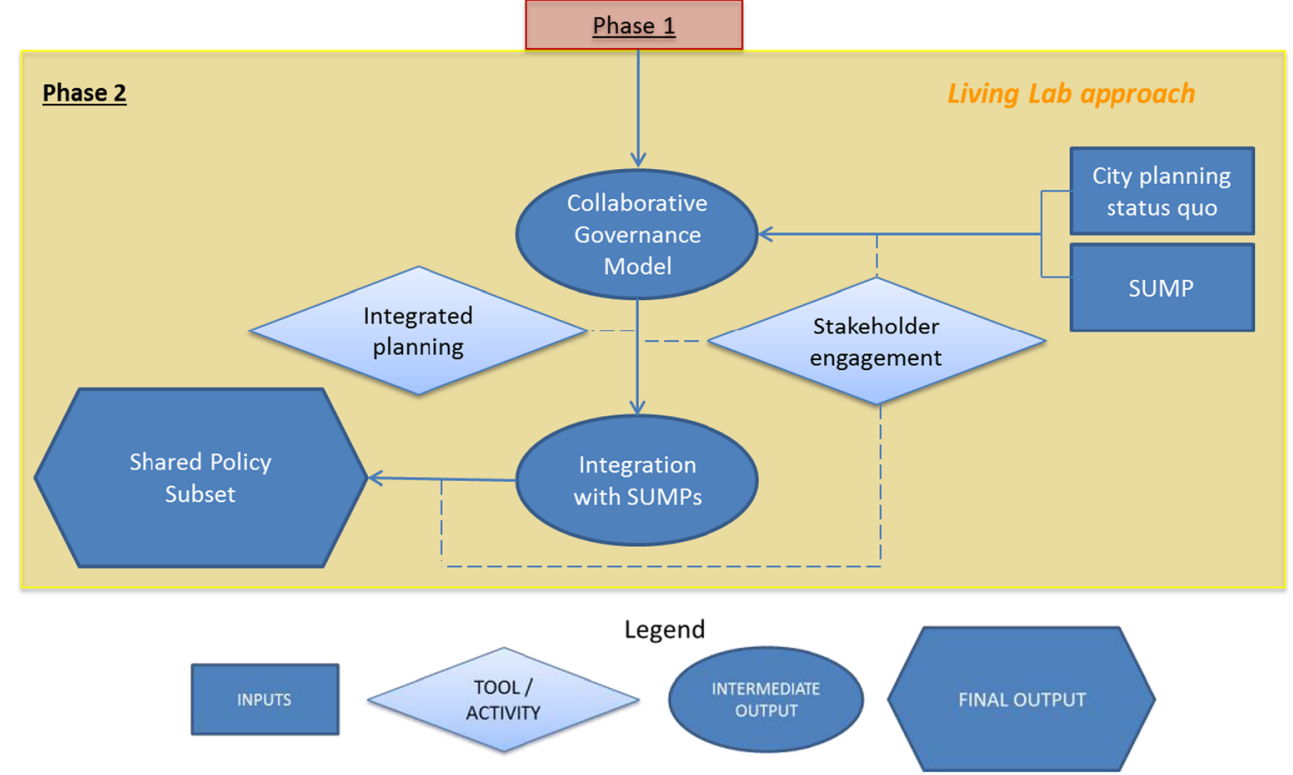

1. Innovative data collection: it complements previous analysis providing additional data for UFT modelling/evaluation. It integrates actively acquired, behaviourally relevant observational data (e.g. face-to-face/internet-based stated preference) with innovative passive data collection methodologies, based on pervasive/low-cost sensing technologies (e.g. GPS and smartphones), producing unprecedented high quality and quantity datasets for model estimation and validation (e.g. [43-45]).

2. Transport Network analysis and simulation: it supports and complements the shared policy sub-set evaluation through a set of simulation models considering performances and flows deriving from the interaction between stakeholders' choices (i.e. the demand generator of freight transport) and transport infrastructures/services (i.e. the supply) [46]. Models allow performing specific assessment tasks, e.g. gauging energy dependence in UFT as already performed with respect to passenger transport analysis [47].

3. Behavioural \& Business Model analysis: it consists of (a) behavioural and (b) economic models to assess stakeholders' policy acceptability and financial viability. Point (a) can be performed using DCM, ABM and a combination of DCM with ABM (see section 2) to consider heterogeneous stakeholders' preferences, explicitly

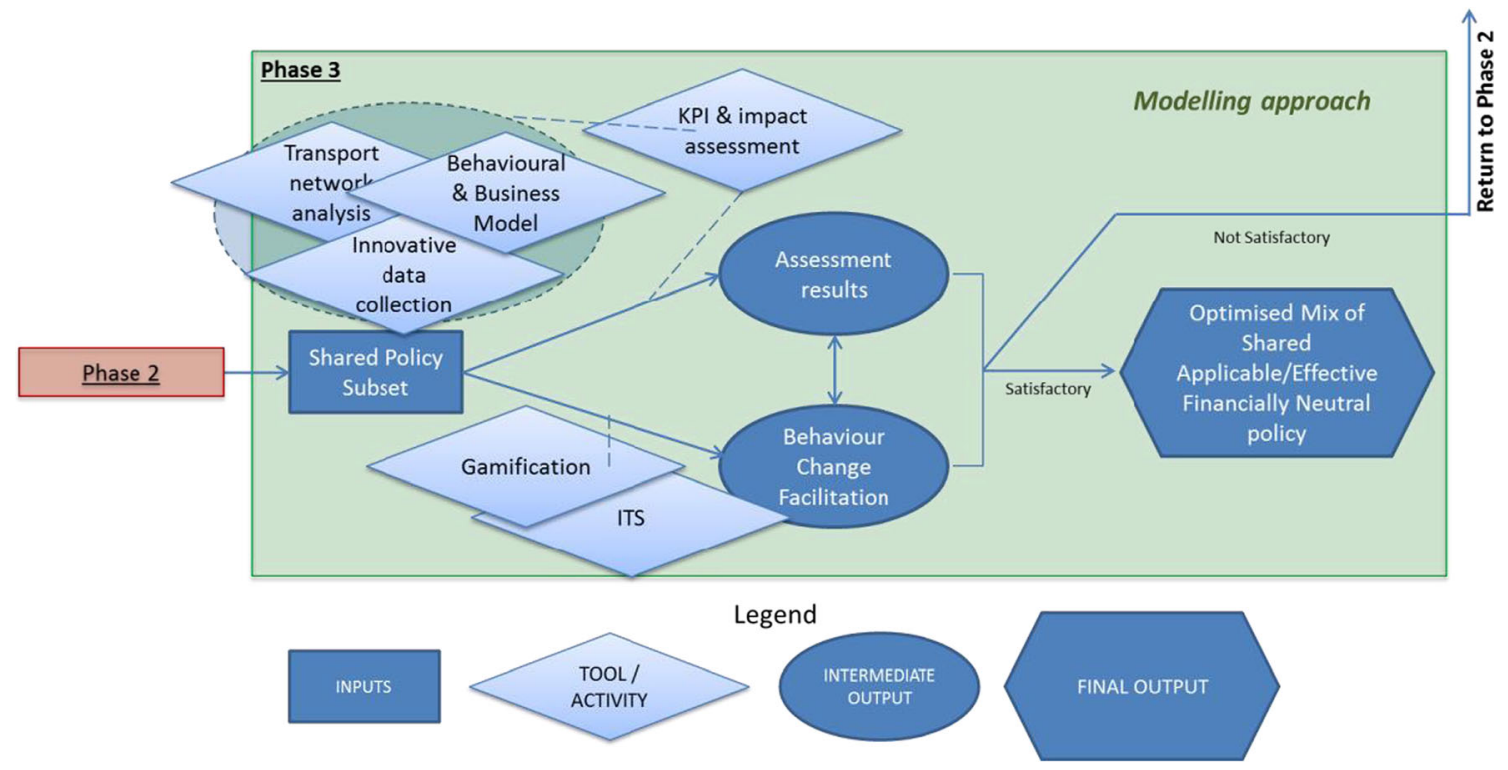

Fig. 4 Description of the third phase "Modelling approach" 
accounting for stakeholders' interactions and ex-ante simulated policy effects [26]. An example of the integration of stakeholders' behavioural analysis within the living lab approach can be found in [48]. Point (b) uses Business Model Canvas techniques [49], providing a clear overview of the most important costs, key resources and activities to exploit, necessary to assess financial viability of the solutions under evaluation. In this respect, the core areas of a Business Model (i.e. infrastructure management, product, customer interface and financial aspects) can be easily transferred to urban logistics, since it implies a business with products/services to be delivered from producers/ suppliers to customers, and the Business Model Canvas can be adapted accordingly, as reported in [14].

4. Key Performance Indicators (KPI) and impact assessment: it consistently describes policy alternatives using suitable and relevant indicators [50] to assess normalised impacts by defining weight criteria, visualising and interpreting results, performing sensitivity analysis and producing an "Overall Joint Satisfaction Index". Typical KPI related to UFT are (increased) load factor, (reduced) vehicle movements, but also financial, social and process indicators (e.g. costs and benefits, new job possibilities generated, customer satisfaction).

5. Gamification: it facilitates behaviour change and is complementary to the planning phases. Context-specific game-design/mechanisms and elements have to be identified early on to boost participation and engagement and the potential impact of a well-thought gamification process on the success of the policy should be assessed in the evaluation phase, i.e. before implementation [33]. Gamification contributes to increase eco-logistics awareness (e.g. eco-labelling, eco-driving, anti-idling) and stimulates pro-active behaviours via a smart use of social media. 6. Intelligent Transport Systems (ITS): they improve logistics flows effectiveness (high service levels) and efficiency (cost reduction) while reducing negative externalities, and their potential effect should be taken into consideration during the evaluation phase [51, 52].
If assessment results are not satisfactory, the process will go back to phase 2 to start a new cycle of the living lab approach and define different policy packages. On the contrary, in case of satisfactory results, the process ends with the definition of an optimised policy mix, derived from a continuous refinement procedure where policies are evaluated via noncorrelated and complementary evaluation tools. This policy mix is likely to be shared (thanks to stakeholder engagement), is applicable/effective, financially sustainable (checked via the assessment results) and easily deployed and adopted (based on behaviour change facilitation tools).

\section{Implications for UFT policy-making}

UFT policy-making is inherently complex. There are no simple solutions to complex problems. Different actors would need to collaborate and coordinate their actions to fine tune the methodology proposed with the aim of producing relevant results and practically demonstrate its flexibility, reliability, comprehensiveness and effectiveness. In this respect, the living lab model, with different layers and feedback loops is fundamental to assure a continuous communication and coordination among actors and a step-by-step decision-making process.

The potential of the proposed methodological approach, still to be practically demonstrated, should be contrasted with the approaches presently used. It is the Authors' conjecture that the methodological approach proposed has a great potential when compared to the disjoint use of the techniques. In fact, it should overcome the main drawbacks of present approaches, by jointly: (1) addressing the problems of incomplete understanding of UFT problems/solutions, scarce coordination between stakeholders and different planning sectors, and lack of ex-ante policy evaluation or, more in general, scant information/understanding of behavioural issues; (2) producing added value in identifying an optimised policy package capable of deploying and supporting cost-effective, shared and environmentally sustainable UFT solutions (Table 1).

Table 1 Comparison of different approaches to UFT policy-making and added value of the proposed integrated framework

\begin{tabular}{|c|c|c|c|c|c|}
\hline & Approach & Problem addressed & Outcome & Effort & Potential of success \\
\hline 1 & Desk & $\begin{array}{l}\text { Incomplete understanding of UFT } \\
\text { problems and solutions }\end{array}$ & $\begin{array}{l}\text { Deep well-grounded } \\
\text { context-embedded knowledge }\end{array}$ & + & + \\
\hline 2 & Living laboratories & $\begin{array}{l}\text { Scant coordination between stakeholders } \\
\text { and different planning sectors }\end{array}$ & Collaborative and integrated planning & ++ & ++ \\
\hline 3 & Modelling & $\begin{array}{l}\text { Lack of ex-ante policy evaluation } \\
\text { and scant information/understanding } \\
\text { of behavioural issues }\end{array}$ & $\begin{array}{l}\text { Evaluation by using different methods } \\
\text { and performing sophisticated analyses }\end{array}$ & ++ & ++ \\
\hline 4 & $(1)+(2)+(3)$ & $\begin{array}{l}\text { Identifying an optimised policy package } \\
\text { and supporting the deployment of } \\
\text { cost-effective UFT solutions }\end{array}$ & $\begin{array}{l}\text { Bringing together knowledge acquisition, } \\
\text { policy co-creation, technical and behaviour } \\
\text { change analysis }\end{array}$ & +++ & +++ \\
\hline
\end{tabular}


Fig. 5 Framework of the overall methodological approach

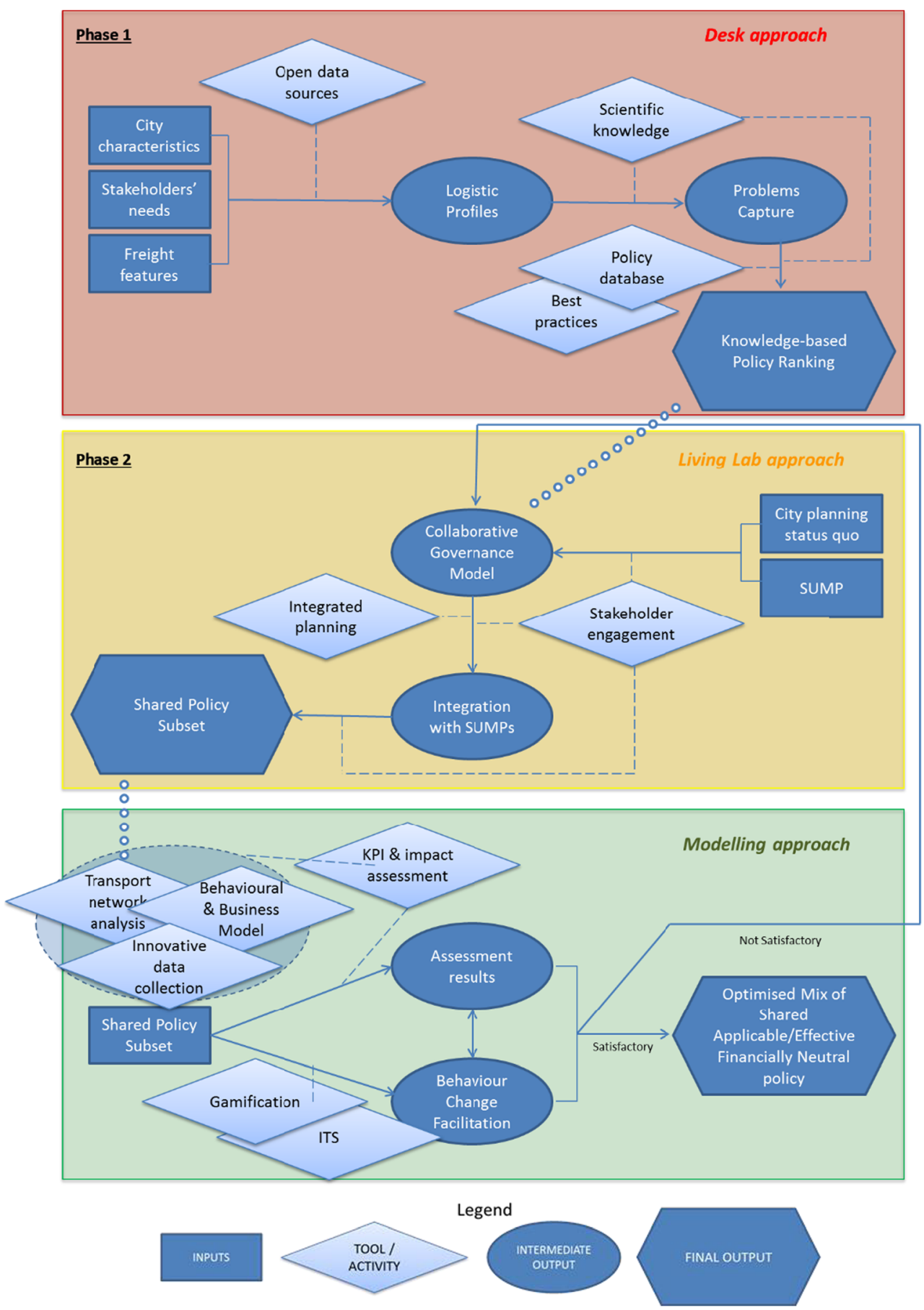

It is important to underline that the methodological approach proposed in this paper innovates in the joint, coordinated and correctly sequenced use of well-accepted and developed techniques that have gained a substantial consensus among researchers and practitioners. The main innovation of the methodological proposal in this paper lies in the selection, sequence and interconnected use of the techniques. This, in fact, innovates while using well-established tools. The main implication for policy-making is guaranteeing both positive impacts for society, short-term policy acceptability and longterm social, environmental and economic sustainability. The sequence of methods proposed, reported in Fig. 5, allows for:

- (stage 1) a pre-selection of policies that accounts for the specific city characteristics and previous policy experiences conducted elsewhere;

- (stage 2) policy co-development, via a living lab approach that refines the set of previously individuated policies also 
allowing for changes, active stakeholder engagement, stimulating a pro-active and inclusive participation of all relevant actors;

- (stage 3) active circular and interrelated policy assessment (see Fig. 4); if the policy mix implemented is not considered satisfactory phase 2 will be re-iterated.

It is clear that an integrated approach requires more effort with respect to using just one technique alone (see Table 1). This is even truer for the desk approach. On the other hand, however, it has a greater potential for success being capable, at least in principle, to overcome the drawbacks single approaches have in identifying an optimised policy package capable of supporting the deployment of effective UFT solutions.

\section{Conclusions}

This paper proposes and discusses a prototypical integrated DSS for local policy-makers and describes a set of procedures, models and tools to select an optimised mix of shared, applicable, effective and financially neutral UFT policy measures, accounting for agents' heterogeneous preferences and deep-routed interactions characterising this complex environment. The three-phase framework proposed integrates diverse approaches/methods and explicitly considers the heterogeneous actors involved. It brings together, within a single methodological approach:

- knowledge acquisition, including all conceivable and updated UFT measures that could apply to the specific city culture, structure and evolution (desk approach);

- policy co-creation, considering all relevant stakeholders and successfully involving them from the beginning (living lab approach);

- behavioural, technical, operational, organisational and financial analysis, identifying the optimised policy package and bringing together all these issues within a single methodological framework (modelling approach).

Local authorities, when dealing with the complexity of urban freight transport policy-making, could use the method proposed as a strategic level DSS since it overcomes the limits of the methods previously used.

Acknowledgements This work was supported by and developed within the framework of the EU H2020 CITYLAB project (grant agreement no. 635898).

Open Access This article is distributed under the terms of the Creative Commons Attribution 4.0 International License (http:// creativecommons.org/licenses/by/4.0/), which permits unrestricted use, distribution, and reproduction in any medium, provided you give appropriate credit to the original author(s) and the source, provide a link to the Creative Commons license, and indicate if changes were made.

\section{References}

1. EU - European Union (2014) Eurostat regional yearbook 2014. Luxembourg: Publications Office of the European Union. ISBN 978-92-79-38906-1 ISSN 2363-1716

2. Cascetta E, Carteni A, Pagliara F, Montanino M (2015) A new look at planning and designing transportation systems: a decisionmaking model based on cognitive rationality, stakeholder engagement and quantitative methods. Transp Policy 38:27-39

3. Taylor, MAP (2005) The city logistics paradigm for urban freight transport. Proceedings of the 2nd State of Australian Cities Conference, Urban Research Program, Griffith University, Brisbane

4. Holguín-Veras J, Aros-Vera F, Browne M (2015a) Agent interactions and the response of supply chains to pricing and incentives. Econ Transp 4(3):147-155

5. Marcucci E, Stathopoulos A, Gatta V, Valeri E (2012) A stated ranking experiment to study policy acceptance: the case of freight operators in Rome's LTZ. Italian J Reg Sci 11(3):11-30

6. Gatta V, Marcucci E (2016a) Stakeholder-specific data acquisition and urban freight policy evaluation: evidence, implications and new suggestions. Transp Rev 36(5):585-609

7. Marcucci E, Gatta V, Scaccia L (2015b) Urban freight, parking and pricing policies: an evaluation from a transport providers' perspective. Transp Res Part A - Policy Prac 74:239-249

8. Holguín-Veras J, Sánchez-Díaz I (2016) Freight demand management and the potential of receiver-led consolidation programs. Transp Res A Policy Pract 84:109-130

9. Marcucci E, Gatta V, Valeri E, Stathopoulos A (2013) Urban freight transport modelling: an agent-specific approach. FrancoAngeli

10. Gatta V, Marcucci E (2014) Urban freight transport and policy changes: improving decision makers' awareness via an agentspecific approach. Transp Policy 36:248-252

11. ALICE/ERTRAC (2015). Urban Freight research roadmap. Available at: http://www.ertrac.org/uploads/documentsearch/id36/ ERTRAC_Alice_Urban_Freight.pdf

12. Holguín-Veras J, Amaya-Leal J, Wojtowicz J, Jaller M, GonzálezCalderón C, Sánchez-Díaz I, Wang X, Haake DG, Rhodes SS, Frazier RJ, Nick MK, Dack J, Casinelli L, Browne M (2015b) Improving freight system performance in metropolitan areas: a planning guide. NCFRP Rep 33

13. Giuliano G, O’Brien T, Dablanc L, Holliday K (2013) Synthesis of freight research in urban transportation planning. NCFRP Rep 23

14. TURBLOG (2011) Business concepts and models for urban logistics. Deliverable 2, seven framework Programme

15. Quak H, Lindholm M, Tavasszy L, Browne M (2016) From freight partnerships to city logistics living labs - giving meaning to the elusive concept of living labs. Transp Res Procedia 12:461-473

16. Ortúzar JD, Willumsen L (2004) Pianificazione dei sistemi di trasporto. Italian edition of "modelling transport" edited by Cherchi, E. Meloni, I. Hoepli

17. EC - European Commission (2013). A Concept for Sustainable Urban Mobility Plans. Annex to the Communication from The Commission to the European Parliament, the Council, the European Economic and Social Committee and the Committee of the Regions Together towards competitive and resource-efficient urban mobility $\operatorname{COM}(2013) 913$ final

18. ENCLOSE (2015). Guidelines developing and implementing a sustainable urban logistics plan. Deliverable 5.2. In: http://www. enclose.eu/

19. Lozzi, G., Gatta, V., Marcucci, E. (2015). Sustainable urban mobility Plans in Europe: a comparative analysis in selected member states. Paper presented at URBE conference (Rome, 1-2 October 2015). In: http://host.uniroma3.it/eventi/urbe/apfp.php 
20. NOVELOG (2016). New cooperative business models and guidance. Sustainable City logistics. Novelog leaflet, Horizon 2020 Programme

21. CIVITAS (2015) Smart choices for cities making urban freight logistics more sustainable. Ther Deliv 4:6

22. Gatta V, Marcucci E (2016b) Behavioural implications of non-linear effects on urban freight transport policies: the case of retailers and transport providers in Rome. Case Stud Transp Policy 4(1):22-28

23. Marcucci E., Gatta V. (2013). Intra-agent heterogeneity in urban freight distribution: the case of own-account operators. International journal of transport economics, XL/2, 267-286

24. Le Pira M, Inturri G, Ignaccolo M, Pluchino A (2015) Analysis of AHP methods and the pairwise majority rule (PMR) for collective preference rankings of sustainable mobility solutions. Transp Res Procedia 10:777-787

25. Le Pira M, Ignaccolo M, Inturri G, Pluchino A, Rapisarda A (2017) Finding shared decisions in stakeholder networks: an agent-based approach. Physica A: Stat Mech Appl 466:277-287

26. Marcucci E, Le Pira M, Gatta V, Ignaccolo M, Inturri G, Pluchino A (2017) Simulating participatory urban freight transport policy-making: Accounting for heterogeneous stakeholders' preferences and interaction effects. Transportation Research Part E 103:69-86

27. Marcucci, E., Gatta, V., 2017. Investigating the potential for offhour deliveries in the city of Rome: retailers' perceptions and stated reactions. Transportation Research Part A: Policy and Practice (in press). doi:10.1016/j.tra.2017.02.001

28. Deterding S, Dixon D, Khaled R, Nacke L (2011) From game design elements to gamefulness: defining gamification. In proceedings of the 15th international academic MindTrek conference: envisioning future media environments (pp. 9-15). ACM

29. Meloni I, Sanjust B (2015) I-pet individual persuasive eco-travel technology: a tool for VTBC program implementation. Transp Res Procedia 11:422-433

30. Corcoba Magaña V, Muñoz-Organero M (2015) GAFU: using a gamification tool to save fuel. IEEE Intelligent transp syst mag SUMMER 2015:58-70

31. Kazhamiakin R, Marconi A, Perillo M, Pistore M, Valetto G, Piras L, Avesani F, Perri N (2015) Using gamification to incentivize sustainable urban mobility. Smart cities conference (ISC2), 2015 I.E. first international

32. Klemke, R., Kravcik, M., Bohuschke, F. (2014). Energy-efficient and safe driving using a situation-aware gamification approach in logistics. Lecture Notes in computer science (including subseries Lecture Notes in artificial intelligence and Lecture Notes in bioinformatics) 8605, (pp. 3-15)

33. Marcucci E, Gatta V, Le Pira M (2016) Gamification design, stakeholder engagement and behavior change in urban freight transport. Paper presented at $14^{\text {th }}$ WCTR, shanghai $10^{\text {th }}-15^{\text {th }}$ July 2016

34. Crainic TG, Montreuil B (2016) Physical internet enabled Hyperconnected City logistics. Transp Res Procedia 12:383-398

35. Montreuil B (2012) Physical Internet Manifesto: Globally Transforming the way physical objects are handled, moved, stored, realized, supplied and used, version 1.11, www. physicalinternetinitiative.org.

36. CITYLAB (2016). CITYLAB local living lab roadmaps. Deliverable 3.2, Horizon 2020 Programme

37. CITYLAB (2015). Practical guidelines for establishing and running a city logistics living lab. Deliverable 3.1, Horizon 2020 Programme

38. Lucassen, I., Klievink, B., Tavasszy, L.A. (2014). A living lab framework: facilitating the adoption of innovations in international information infrastructures, transport research arena 2014, Paris

39. Asian Development Bank (2007) Guidelines for preparing a design and monitoring framework. Asian Development Bank, Manila
40. Macharis, C. (2005). The importance of stakeholder analysis in freight transport. European transport Trasporti Europei n. 25-26, pp. $114-126$

41. Macharis C., Milan, L., Verlinde, S. (2013). A stakeholder based evaluation framework for city distribution. Selected proceeding of the 13th world conference on transport research (WCTR), 15th18th July 2013, Rio de Janeiro, Brazil. ISBN: 978-85-285-0232-9

42. Wefering F, Rupprecht S, Bührmann S, Böhler-Baedeker S (2014) Guidelines. Developing and Implementing a Sustainable Urban Mobility Plan. Rupprecht Consult - Forschung und Beratung GmbH

43. Heipke C (2010) Crowdsourcing geospatial data. ISPRS J Photogramm Remote Sens 65:550-557

44. Gal-Tzur A, Grant-Muller SM, Kuflik T, Minkov E, Nocera S, Shoor I (2014) The potential of social media in delivering transport policy goals. Transp Policy 32:115-123

45. Stathopoulos, A., Cirillo, C., Cherchi, Ben-Elia, E., Li, Y-T., Schmöcker, J-D. (2017). Innovation adoption modeling in transportation: new models and data. Journal of Choice Modelling (in press). doi:10.1016/j.jocm.2017.02.001

46. Cascetta E (2009) Transportation system analysis. Models and applications (2nd edition ed.). Springer, New York

47. Ignaccolo $\mathrm{M}$, Inturri $\mathrm{G}$, Le Pira $\mathrm{M}$, Caprì S, Mancuso V (2016) Evaluating the role of land use and transport policies in reducing the transport energy dependence of a city. Res Transp Econ 55:60-66

48. CITYLAB (2017). Urban freight status of the CITYLAB living labs and behaviour change/willingness to pay analysis. Deliverable 2.2, Horizon 2020 Programme

49. Osterwalder, A., Pigneur, Y. (2010). Business model generation: a handbook for visionaries, game changers, and challengers. Published by John Wiley \& Sons, Inc., Hoboken. New Jersey

50. Kaparias, I., Bell, M.G.H. (2011). Key performance indicators for traffic management and intelligent transport systems. EU FP7 funded CONDUITS project, contract no. 218636 Deliverable no. 3.5. http://www.conduits.eu/Deliverables.asp

51. Taniguchi E, Thompson RG, Yamada T, van Duin R (2001) City logistics - network modelling and intelligent transport systems. Pergamon

52. Crainic TG, Gendreau M, Potvin J (2008) Intelligent Freight Transportation Systems: Assessment and the Contribution of Operations Research. CIRRELT-2008-40.

\section{Reference list of UFT-related EU projects}

BESTFACT (2012-2015). Best practice factory for freight transport. EU Framework Programme 7

BESTUFS I (2000-2004). Best urban freight solutions. EU Framework Programme 5

BESTUFS II (2004-2008). Best urban freight solutions. EU Framework Programme 6

C-LIEGE (2011-2013). Clean last mile transport and logistics management. EU IEE

CITYFREIGHT (2002-2004). Inter- and intra- city freight distribution network. EU Framework Programme 5

CITYLAB (2015-2018). City logistics in living laboratories. EU H2020 project

CITYLOG (2010-2012). Sustainability and efficiency of city logistics. EU Framework Programme 7

CIVITAS I (2002-2006). Projects: MIRACLES, TELLUS, TRENDSETTER, VIVALDI

CIVITAS II (2005-2009). Projects: CARAVEL, MOBILIS, SMILE, SUCCESS

CIVITAS PLUS (2008-2012). Projects: ARCHIMEDES, ELAN, MIMOSA, MODERN, RENAISSANCE 
CIVITAS PLUS II (2012-2016). Projects: DYN@MO, 2MOVE2

LAMILO (2013-2015). Last mile logistics. EU Interreg IVB

NICHES (2004-2007). New and innovative concepts for helping European transport sustainability. EU Framework Programme 6

SMARTSET (2013-) sustainable market driven terminal solutions for efficient freight transport. EU IEE
SUGAR (2008-2012). Sustainable urban goods logistics achieved by regional and local policies. EU Interreg IVC

TIDE (2012-2015). Transport innovation deployment in Europe. EU Framework Programme 7

TURBLOG (2009-2011). Transferability of urban logistics concepts and practices from a worldwide perspective. EU Framework Programme 7 